\title{
EDUCACIÓN Y SUPRANACIONALIDAD: APROXIMACIÓN A LOS CONCEPTOS BÁSICOS
}

\section{EDUCATION AND SUPRANATIONALITY: APPROACH TO THE BASICS}

\begin{abstract}
Throughout the following pages we'll find a text whose character is eminently didactic. The aim of this text is to show a conceptual approach to the supranational policies of education and its impact on the historical context and contemporary society. For this, we go into the notion of education, politics and education policy, by means of reference authors that help us to delimit and define the meanings of the proposed terms. Afterwards, we made an approach to the concepts of globalization and supranationality, delve into the determining factors that have led us to develop the globalized society presently and we delimit the concept of supranationality, its political connotations and its repercussion. Finally, we describe the object of study of the supranational policies of education as a young discipline in the field of international education, as well as its origin, its evolution and its current reality.
\end{abstract}

María Matarranz

Javier M. Valle

Key words: Education, education policy, globalization, internationalization, supranational policies of education

\section{RESUMEN}

A lo largo de las siguientes páginas encontramos un texto cuyo carácter es eminentemente didáctico. El objetivo del presente texto es realizar una aproximación conceptual a la política educativa supranacional y su impacto en el contexto histórico y la sociedad contemporánea. Para ello, nos adentramos en la reflexión de los términos educación, política y política educativa, por medio de autores de referencia que nos ayudan a delimitar y definir los significados de los términos propuestos. Posteriormente, realizamos una aproximación a los conceptos de globalización y supranacionalidad, profundizamos sobre los factores determinantes que nos han llevado a desarrollar la sociedad mundializada en la que nos encontramos y acotamos el concepto de supranacionalidad, sus connotaciones políticas y su repercusión. Finalmente, se describe el objeto de estudio de la política educativa supranacional como una joven disciplina en el ámbito de la educación internacional, así como su origen, su evolución y su realidad actual.

Palabras clave: Educación, política educativa, globalización, internacionalización, política educativa supranacional.

Fecha de recepción: 11 de enero de 2019

Fecha de aceptación: 29 de enero de 2019 


\section{DEFINIENDO LOS CONCEPTOS BÁSICOS}

\subsection{EDUCACIÓN}

El término educación está ligado a la vida cotidiana. A todos los seres humanos les afecta ya que en algún momento de su vida han sido educados, a todo ser humano le enseñaron cosas, forma parte de su vida y de su contexto social, en este sentido, Estévez (2010) afirma que la educación, es un proceso que se inicia en el mismo momento del nacimiento y que debe conducirnos a entendernos a nosotros mismos y a entender el mundo que nos rodea. Conceptualmente hablando asumimos que el término de educación está limitado por la subjetividad de quien lo defina, es más, podemos decir que la educación es un concepto histórico y socialmente determinado, pues el concepto de educación se ha ido modificando a lo largo de la historia en función de la mentalidad dominante. A este respecto, Savater (1997) indica que "bajo el mismo rótulo de educación se acogen fórmulas muy distintas en el tiempo y en el espacio" (p. 43). Si bien, el denominador común de todas esas concepciones es que el término educación está ligado a lo que consideramos deseable en una persona, la búsqueda del ideal de perfección humana a través de la educación ha sido una realidad histórica. En este sentido cabe rescatar el texto de Platón donde define la educación en los siguientes términos:

Decimos que tal persona es educada y tal otra ineducada, aplicando aquella expresión a veces a un hombre grandemente instruido en lo relativo al comercio al pormenor, o en la navegación o en otras cosas semejantes. Pero nuestra argumentación no puede ser, claro está, la de aquellos que creen que tales cosas constituyen la educación, sino la de los que piensan en la educación para la virtud desde la infancia, que hace al niño deseoso y apasionado de convertirse en un perfecto ciudadano, con saber suficiente para gobernar y ser gobernado en justicia. Definiendo nuestro argumento esta crianza, sólo a ella, según creo, consentiría en llamar educación; mientras a la que se endereza a los negocios o a un determinado vigor físico o a algún conocimiento no acompañado de razón y justicia, la tendría por artesana y servil e indigna de ser llamada educación en absoluto. (Platón, en Ibáñez Martín, 2010, p. 7)

En la medida en que cambia lo deseable, cambia el concepto educación; hay tantas perspectivas de educación porque a lo largo de la historia el hombre ha ido modificando el concepto de lo deseable. Tal y como afirma Peters (1969) la educación es inseparable de los juicios de valor; hablar de educación es inseparable de hablar de lo que se considera valioso. Dado que cada individuo alberga una subjetividad propia, resulta lógico que "de diferentes criterios morales se considerarán como deseables diferentes metas educativas, pues las personas defendemos diferentes concepciones de qué es lo «deseable» y lo que perfecciona al hombre" (Estévez, 2010, pp. 50-51). Frente a esta versatilidad conceptual, resulta conveniente que la educación no sea una mera convención histórica.

Conocer el origen etimológico de las palabras nos ayuda a entender el sentido original que estas encierran, aunque el significado de las palabras en ocasiones varía con el paso del tiempo, su sentido original ilumina parte del significado que en la actualidad les reconocemos, "las palabras tienen su historia, y podrían evitarse numerosas discusiones si se procurara precisar muy bien el sentido con que se las utiliza" (Mialaret, 1977, p. 11). El término educación es un claro ejemplo de ello, que como decíamos, su concepto ha ido variando con el paso del tiempo: desde una perspectiva etimológica hallamos dos acepciones latinas que guardan una estrecha relación entre sí:

(1) Educare (educ-are): cuyo significado es criar, alimentar, cuidar... Desde esta perspectiva se entiende la educación como una influencia humana que sirve de guía, influencia cuyos fines están determinados, en muchas ocasiones, por el logro de unos objetivos medibles y cuantificables, así 
pues, la educación en este sentido será el proceso por el cual un individuo adquiere aprendizajes valiosos tanto para su propio desarrollo como para el desarrollo de la sociedad en la que vive, siendo esencial la presencia de un guía que acompañe ese proceso educativo.

(2) Educere (educ-ere): su significado es salir, extraer, sacar de dentro hacia fuera, perspectiva desde la cual se concibe la educación como el instrumento que permite que el hombre llegue a ser lo que es. Sin educación no habría humanización, la educación genera cambios en el individuo humanamente valiosos, apela a los cambios más profundos del ser humano. Así bien, independientemente del momento histórico, de manera universal la educación es siempre un cambio de estado deseable y, como tal, el elemento central de la educación es el sujeto que se educa: el educando.

Ambas raíces etimológicas nos llevan a significados del término que, a día de hoy, son pertinentes, sin embargo, podemos observar una clara diferencia entre ambas. La primera acepción centra su atención en la importancia del educador como eje de la acción educativa, el educador es aquel que acompaña o guía; mientras que en la segunda acepción el centro de atención pasa a ser el educando como aquel que genera un cambio de valor en sí mismo. Otros autores de gran relevancia en el área educativa (Perez Juste, 2002; Delors, 1996; Morin, 2005) coinciden en afirmar que la educación es el máximo desarrollo integral de la persona a fin de alcanzar una mejora o perfeccionamiento tanto a nivel individual como a nivel social.

Educar en consecuencia es, un cambio de estado deseable, tanto a nivel individual como a nivel social. Esto es, se educa para lograr el máximo desarrollo integral de la persona, si los procesos educativos que hoy conocemos tuvieran como máxima esta finalidad, podría plantearse que, al alcanzar el máximo desarrollo de la persona, se podría llegar al desarrollo máximo social.

\subsection{Política y Política Educativa}

Siguiendo con la perspectiva etimológica de los conceptos que abordamos, el término política, hunde sus raíces por un lado en el latín politĭcus, adjetivo de político y por otro lado en el griego politikós, politikế y polis, ciudadanos, ciudadano y ciudad respectivamente. En consecuencia, podemos referirnos a la política como la cuestión que implica a los ciudadanos y los asuntos públicos que constituyen su vida.

A lo largo de la historia, numerosos pensadores, filósofos, estudiosos y escritores han tratado de realizar una aproximación sobre la política, su definición y su objeto. Podemos comenzar esta aproximación conceptual refiriéndonos a Sócrates, Platón o Aristóteles, entre otros muchos, filósofos que se preocuparon por la vida política de su época y que consideraban que la política era un elemento determinante para el orden social y, por tanto, esencial para que los individuos pudieran vivir felizmente. La filósofa Arendt (1997), por su parte, concebía la política como:

Una necesidad ineludible para la vida humana, tanto individual como social. Puesto que el hombre no es autárquico, sino que depende en su existencia de otros, el cuidado de ésta debe concernir a todos, sin lo cual la convivencia sería imposible. Misión y fin de la política es asegurar la vida en el sentido más amplio. (p. 67).

Hague definió la política como "la actividad a través de la cual los grupos humanos toman decisiones colectivas" (Hague et al., 1994, en Aguila, 2008, p. 21). Asimismo, encontramos en la enciclopedia de pensamiento político dirigida por Miller (1989) el concepto de política en los siguientes términos "proceso por el que un grupo de personas, cuyas opiniones son en principio divergentes, toman decisiones colectivas que, por lo general, se consideran obligatorias para el 
grupo y se ejecutan de común acuerdo" (p. 518). Sartori (1993), en su libro sobre democracia, hace la distinción conceptual entre el político y la política, el sustantivo y la sustantivación, afirmando que:

Político es una persona y se puede hacer toda una tipología, por una parte, se pone al político "realista" y por la otra al político "idealista". Con esto se quiere decir que hay hombres políticos sin prejuicios, sin principios, que sólo buscan satisfacer sus intereses en términos de poder, y otros políticos que, en cambio, tienen la mirada fija en el idealismo que persiguen. La política, en cambio, es un proceso, incluso a largo plazo, el cual involucra a muchísimas personas y que, al menos en nuestros días, exige adhesión y participación. (p. 28)

Por su parte el profesor Sodaro (2006) afirma que

La política es el proceso por el que las comunidades persiguen objetivos colectivos y abordan sus conflictos en el marco de una estructura de reglas, procedimientos e instituciones, con el objetivo de alcanzar soluciones y adoptar decisiones aplicables por la autoridad estatal (en sus diferentes niveles político-administrativos) al conjunto de la sociedad...La política se ocupa de cómo organizan las personas sus comunidades con el propósito de tratar colectivamente a los problemas a los que se enfrentan. (pp. 1-2).

Como vemos, los autores mencionados coinciden en señalar ciertos elementos esenciales que forman parte de la política:

(1) en primer lugar, que la política es una actividad que nace como fruto de un proceso y como tal, dicho proceso consta de un diálogo por parte de todos los agentes implicados;

(2) el objeto del diálogo establecido es la búsqueda del bien común, es decir, la finalidad del diálogo es hallar un punto de encuentro que permita discernir los caminos para el progreso de la sociedad y el bienestar de sus individuos;

(3) en todo caso, implica la puesta en marcha de acciones que se consideran beneficiosas para los ciudadanos y que afectan al conjunto de la sociedad;

(4) tanto por la repercusión de las acciones puestas en marcha, como por la participación requerida para la toma de decisiones y la ejecución de dichas acciones, afecta e involucra al conjunto de la sociedad.

Dando un paso más, cuando hablamos de política educativa, tradicionalmente entendemos que es aquello que el Estado hace en materia educativa, esto es, la intervención que el Estado tiene para conseguir determinados objetivos en educación. Esta concepción muestra, sin duda, una clara delimitación geográfica, dado que las acciones que el Estado pone en marcha se aplican dentro de las fronteras nacionales.

Su objeto de estudio es la influencia de la política en los sistemas educativos, con la implicación de todos los actores que intervienen tanto en educación como en política, así como el estudio de los procesos que los acompañan. En consecuencia, cuando hablamos de política educativa nos referimos, por un lado, a las actividades y decisiones concretas que en materia educativa ha tomado una institución en un momento determinado. Es decir, a la legislación educativa propiamente dicha. Esta concepción de la política fue durante mucho tiempo, la única forma de entender el término, así bien, desde esta perspectiva la política educativa es asunto de los gobiernos o de los Estados, incluso de los organismos internacionales y supranacionales, que establecen unos objetivos y unas ideologías encaminadas a la consecución de esos objetivos, y que se ponen en marcha a través de acciones en un marco legislativo concreto. Por otro lado, hablamos de política educativa cuando hacemos referencia al conocimiento político que se aplica a la educación y que introduce lo valorativo, este enfoque no supone renunciar al estudio de las políticas educativas de carácter 
instrumental o medial sino que asumiéndolo trata también de conocer esa otra vertiente de la realidad que es el conflicto educativo, las relaciones de la educación con el poder y la relación de los fines con los medios. Puelles (2004) afirma que la política educativa es "la ciencia social que estudia la educación como fenómeno político” (p. 35). Y que, además, añade todo el entramado que acontece antes, durante y después la aplicación de la ley.

Esta doble significación del término política educativa, tal y como nos indica Manuel de Puelles (2004), en la lengua inglesa utiliza términos diferenciados para referirse a ella:

(1) Policy refiere a los programas de acción en un campo educativo, medidas orientadas a la consecución de un objetivo, en definitiva, las leyes educativas. Pretende hacer de la política un conocimiento científico. Se deriva de aquí la ciencia política; para referirse a la toma de decisiones y acuerdos. Este concepto de la política, está vinculado con un plano de interpretación jurídico, dado que centra su atención en conocer las normas jurídicas existentes para poder interpretar qué ocurre en el sistema educativo.

(2) Politics refiere a conflictos, acciones que responden a ideologías concretas y a los conflictos que generan. Aparece el sistema de valores que sustenta esas acciones. Estos componentes describen las funciones que tiene la educación y analiza y valora si están bien o no. El problema añadido que encontramos en estos componentes es que influyen los valores personales. Desde la perspectiva de la politics, nos encontramos ante un plano de interpretación crítico, dado que establece una justificación y valoración de las decisiones y acciones en política educativa, nos habla de aspiraciones ético-sociales, del ideal social. Este plano crítico incluye una visión pedagógica ya que implica pensar desde un punto de vista educativo. La reflexión crítica y el análisis de los procesos que configuran la elaboración de políticas educativas está vinculado al pensamiento pedagógico, ya que supone conocer su origen, su desarrollo y su proceso de maduración, así como valorar el impacto de las acciones puestas en marcha en materia educativa. Esta dualidad del término política educativa, queda reflejada en la figura 1.

Figura 1: Dualidad de la política

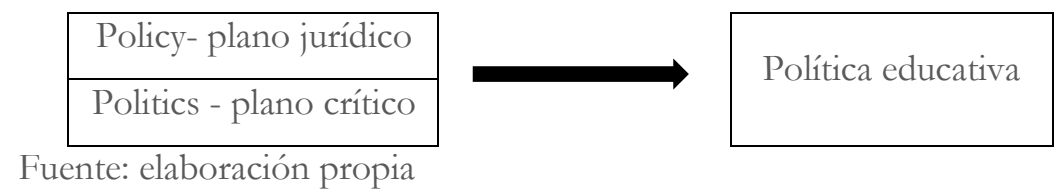

En definitiva, entendemos política educativa como el proceso a través del cual se ponen en marcha decisiones y acciones en materia educativa que tienen su origen en un diagnóstico y una detección de necesidades reales y cuya orientación, por un lado, es dar respuesta a dichas necesidades, y por otro es la consecución de unos logros o unos objetivos concretos, en un contexto y unas circunstancias determinadas. Para que la política educativa adquiera pleno sentido en su significado, debemos incluir el seguimiento de dichas decisiones, de forma que se garantice la correcta aplicación de las mismas, así como una evaluación que permita conocer si las acciones puestas en marcha dan respuesta real a las necesidades detectadas y si se orientan de manera adecuada al logro de los objetivos establecidos. Y (no por estar en último lugar menos importante) un análisis del impacto de dichas políticas en los sistemas educativos.

En el análisis de las políticas educativas resulta imprescindible tener en cuenta los actores que intervienen en ellas, sin los cuales sería impensable su puesta en marcha.

Los actores de las políticas educativas son aquellos que forman parte del proceso educativo, y que abarca desde los elementos más cercanos al propio sujeto protagonista del proceso de enseñanza- 
aprendizaje, hasta los elementos más lejanos, pero todos ellos implicados de manera activa y directa en las políticas educativas:

- El Estado: es el macrosujeto por excelencia que ejerce un papel esencial en las políticas públicas en general y en las políticas educativas en particular.

- Las Organizaciones Internacionales: instituciones que ejercen influencia en los sistemas educativos nacionales proponiendo acciones en educación que progresivamente van permeabilizando en las políticas educativas de los países miembros.

- Los partidos políticos: como elementos determinantes y sujetos activos dentro de las políticas. Los partidos políticos son sin duda elementos influyentes en las orientaciones de las políticas que se elaboran en materia educativa, así bien, cada partido político tiene unas inclinaciones ideológicas diferenciadas que les llevan, evidentemente, a hacer propuestas políticas diferenciadas.

- Los grupos de presión: son aquellos grupos sociales (empresas, asociaciones, sindicatos o agrupaciones de carácter económico, social o profesional) que defienden sus intereses dentro de la legalidad democrática. Creando grupos de presión, denominados lobbys que hacen de hecho política, pero que no asumen por ello ninguna responsabilidad al respecto. (Puelles, 2004)

- Los sistemas educativos: Un sistema educativo es un conjunto de instituciones que se ocupan de la educación y de la formación (Lesourne, 1993). Los sistemas educativos son sistemas complejos con multitud de elementos, tales como la organización escolar, el currículo, la formación del profesorado, la financiación, la administración educativa o la dirección escolar (entre otros muchos) que influyen en ellos, y que se relacionan entre sí.

- Las escuelas: agente que imparte las pautas de comportamiento del discente, al mismo tiempo que es transmisor de unas orientaciones políticas. Las escuelas también son aquellos agentes en quienes se positivizan todas las acciones políticas en materia educativa y sin duda son también el motor de cambio social.

- Las familias: junto con la escuela es un factor de primer orden para la socialización del individuo, y para establecer las pautas de comportamiento social en el individuo. Así bien, las bases para el desarrollo de ciudadanos activos, responsables, cívicos y democráticos, las localizamos en las familias y en las escuelas.

- Los valores: son inherentes a cualquier elemento de la sociedad. Las leyes, como parte esencial del orden social albergan dentro de sí valores e ideologías. Entendemos como valores políticos aquellos significados, asumidos por la sociedad, que portan los objetos y relaciones políticos según su capacidad para articular soluciones que contribuyan a satisfacer las necesidades socialmente reconocidas y conservar el poder que hace posible lo anterior. Cuando se percibe incongruencia entre los contenidos de los valores y su realización en políticas que tiendan al logro de bienes sociales concretos, se genera una tensión entre la realidad y los valores que habrán de remediar sus penurias. (Salabarría Roig, Conferencia Internacional, 2006).

La legislación en materia educativa, como ya se ha definido, es la puesta en marcha de acciones o directrices para resolver conflictos o atender necesidades educativas. Estas directrices no están exentas de los valores e ideologías de aquellos grupos sociales que las elaboran, es más, cada una de las políticas elaboradas en materia educativa, contiene unos valores e ideologías específicas, y desde ellas es desde donde trata de darse respuesta a los conflictos existentes en educación. La detección de dichos valores e ideologías, así como reconocer su impacto en los sistemas educativos es un paso fundamental para analizar las políticas puestas en marcha. 
En pleno siglo XXI ni la educación, ni la política pueden sustraerse a los procesos de globalización, por ello abordamos a continuación la perspectiva global y supranacional de los procesos políticos en materia educativa.

\section{GLOBALIZACIÓN Y SUPRANACIONALIDAD: LA REALIDAD DEL SIGLO XXI}

En las últimas décadas se han sucedido una serie avances científicos, tecnológicos y sociales que han afectado a todas las esferas del ser humano, produciéndose cambios y transformaciones en las formas de vida, de relacionarse y de entenderse (Colucci-Gray \& Gray, 2014). Así bien, ligado a los conceptos de educación, política y política educativa ya vistos, nos encontramos con los términos globalización y supranacionalidad.

¿Cómo podrían los ciudadanos del nuevo milenio pensar sus problemas y los problemas de su tiempo? Es necesario que comprendan tanto la condición humana en el mundo como que comprendan la condición del mundo humano que, a lo largo de la historia moderna se ha convertido en la de la era planetaria. Desde el siglo XXI hemos entrado en la era planetaria y, desde finales del siglo XX, nos hallamos en el estadio de la mundialización. (Morin, 2005, p. 75).

El término globalización, hace referencia a una serie de transformaciones que ha hecho la vida económica más competitiva y más exigente. En su origen fue un movimiento instigado por la integración de las economías y las sociedades a través de flujos de información, tecnologías, servicios, capitales y personas, y es en este contexto en el que se desarrollan los individuos y las sociedades (Kumar \& Parveen, 2013).

Es una realidad que el fenómeno de la globalización ha impactado en el día a día de todos nosotros, cuestionando incluso la existencia de fronteras nacionales y acercando aquello que antes era prácticamente inaccesible (información, personas, países, etc.). En consecuencia, nuestras formas de relacionarnos, dialogar y tomar decisiones también se han modificado, es decir, nuestra forma de ver y hacer política ha cambiado.

La globalización ha impactado en diferentes ámbitos, siendo el ámbito educativo uno de ellos, es más, podríamos decir que el fenómeno que más impacto tiene en el ámbito educativo es la globalización, que incluye dentro de sí los avances de las nuevas Tecnologías de Información y Comunicación (TIC), así como los cambios sociales y culturales. Estas novedades han afectado a nuestra identidad, sentido de la vida, y relaciones con los demás, de tal manera que estos procesos sociales y culturales de cambio han repercutido directamente en las ciencias sociales (López, 2008). Como decimos, este proceso ha impactado en todas las áreas de la sociedad, si bien podemos decir que la educación ha sido uno de los ámbitos que más influenciado se ha visto.

De la mano de los procesos de globalización, nuevas formas de poder y gobierno han ido ganando fuerza e influencia al margen de la política, es decir, sin haber sido tratadas en colectivo, consensuadas, ni necesariamente persiguiendo objetivos comunes a la mayoría de la sociedad. Un aspecto clave consecuencia de la globalización es el surgimiento de nuevas corrientes culturales y educativas, y la apertura hacia conceptos políticos supranacionales dirigidos hacia la construcción de un proyecto común y una sociedad mundial (López, 2008).

Con respecto al término supranacionalidad, sus orígenes los localizamos retrocediendo en el tiempo hasta finales de la Segunda Guerra Mundial. De todos es conocida la devastación de los países que participaron en esta Guerra, y la situación desoladora que dejó a su término. Dadas las circunstancias, resulta necesaria la búsqueda y creación de acuerdos con dos objetivos claros: 
- Evitar nuevos conflictos de semejante envergadura entre países.

- Reconstruir el paisaje en ruinas que había dejado la Guerra.

La creación de organismos internacionales y supranacionales surge, en consecuencia, con el objetivo fundamental de establecer caminos de paz, diálogo y solidaridad a fin de reconstruir todo lo que la Guerra había destruido (Valle, 2006; Matarranz, 2017). Así bien, el concepto supranacional, aparece por primera vez con el Tratado internacional que funda la Comunidad Europea del Carbón y del Acero (CECA, 1951), la cual adquiere, por primera vez en la historia, una capacidad de decisión superior a la de los propios países que forman parte de ella.

La delimitación del concepto supranacional y su naturaleza jurídica y política fue objeto de debate por distintos expertos, incluidos los padres fundadores de la CECA, desde el nacimiento de aquella primera Comunidad Europea. Algunas personas veían en esta institución una categoría jurídica absolutamente novedosa, otras personas la veían como el resultado de una evolución necesaria tras la Guerra, siguiendo este argumento podemos afirmar que, más allá de los distintos puntos de vista y opiniones sobre la creación de esta primera institución con carácter supranacional, el hecho en sí ya era buena muestra de que, por encima de todo, define un conjunto de características que imprimen en las comunidades europeas un carácter original que las distingue de manera definitiva del resto de organizaciones internacionales.

En esta nueva conformación cada Estado miembro deposita parte de la propia soberanía al grupo, sobreponiendo los acuerdos y decisiones que se toman dentro del organismo, al marco político y legal del propio Estado. Se establece entonces una diferencia clave con los anteriores organismos internacionales, donde los miembros mantenían intacta su soberanía y participaban (o no) de forma voluntaria en los acuerdos y propuestas que se tomaban. De tal manera que, a partir de este momento emerge un nuevo concepto "supranacionalidad", que va a ir ampliándose progresivamente hasta llegar al ámbito de la educación. (Matarranz \& Pérez, 2016).

Ejemplo de ello es la aparición de organismos internacionales y su implicación cada vez más intensa en acciones de carácter educativo, lo cual va promoviendo una progresiva armonización en las formas de entender las grandes cuestiones que afectan a la política educativa. Cabe señalar también el incremento de la movilidad de estudiantes, profesores e investigadores, que da lugar al intercambio de conocimientos y al "trasvase de ideas y prácticas pedagógicas que va permeabilizando todos los países y deriva poco a poco en grandes corrientes educativas que se extienden cada vez con más rapidez" (Valle, 2012, p. 112).

\section{Política EDUCATIVA SUPRANACIONAL: EL CAMPO DE ESTUDiO EMERGENTE}

Las características planteadas por el fenómeno de la globalización no pueden ser estudiadas utilizando únicamente enfoques tradicionales de las ciencias sociales, de ahí la necesidad de generar debates continuos que ayuden en la renovación de los procesos y métodos de investigación científica. Fruto de ello, resulta innegable asumir que este contexto ha trazado nuevos escenarios políticos y educativos sobre los que se han ido construyendo y fundamentando las bases de una nueva disciplina científica y académica: la política educativa supranacional.

"Los límites nacionales resultan insuficientes para dar cuenta de qué son en realidad los sistemas educativos, cuáles son sus metas y hacia dónde evolucionan” (Tiana, 2009, p. 10). Así bien, la política educativa supranacional, se encargará de estudiar los fenómenos educativos a nivel internacional, superando así las barreras nacionales, y tratando de detectar cuál es el impacto que 
tienen en los sistemas educativos nacionales las políticas educativas que emanan de los organismos internacionales y supranacionales.

Desde el punto de vista de la política supranacional es importante tomar conciencia que, desde dichos organismos internacionales o supranacionales, llegan a asumirse decisiones que se materializan en acciones concretas generando un impacto en dichos países. Las políticas que emanan de organismos internacionales y supranacionales son cada vez más acogidas a nivel nacional, construyendo poco a poco una realidad compartida que traspasa las fronteras nacionales. Así, la política educativa supranacional, como área de estudio emergente, centra su estudio en las políticas educativas de los organismos internacionales que progresivamente van influyendo y generando cambios en los sistemas educativos nacionales. Siendo este el objeto de estudio más amplio, cabe señalar que la concreción de la política educativa supranacional puede tener distintas orientaciones (Valle, 2012). Así bien, destacamos, tal y como vemos en la tabla 1, algunas de las líneas de estudio más significativas para la disciplina que nos ocupa. Estos ámbitos de estudio de la Política Educativa Supranacional arrojarán luz a las políticas que nacen, se desarrollan y se llevan a cabo instigadas por el impulso inicial de los organismos internacionales.

Tabla 1: Ámbitos de estudio de la política educativa supranacional y ejemplos aplicados.

\begin{tabular}{|l|l|}
\hline ÁMBITOS DE ESTUDIO & \multicolumn{1}{|c|}{ EJEMPLOS APLICADOS } \\
\hline $\begin{array}{l}\text { Análisis de las políticas } \\
\text { educativas de Organismos } \\
\text { internacionales }\end{array}$ & $\begin{array}{l}\text { Análisis supranacional de la política educativa de la unión europea } \\
\text { 2000-2015. Hacia un espacio europeo de educación. (Matarranz, 2017) } \\
\text { Política educativa de la UNESCO: Reflexiones desde un modelo de } \\
\text { análisis supranacional. (Fernández-Represas, 2015) }\end{array}$ \\
\hline $\begin{array}{l}\text { Análisis comparado de las } \\
\text { políticas de organismos } \\
\text { internacionales. }\end{array}$ & $\begin{array}{l}\text { Concepciones de la OCDE y la Unión Europea sobre el Desarrollo } \\
\text { Profesional Docente (Monarca y Manso, 2016) }\end{array}$ \\
\hline $\begin{array}{l}\text { Equidad de género en las agencias supranacionales. Evidencias } \\
\text { educativas desde una lectura comparada (Usarralde, 2015) }\end{array}$ \\
$\begin{array}{l}\text { Estudio de la repercusión y el } \\
\text { sistemas educativos nacionales. }\end{array}$ & $\begin{array}{l}\text { Impacto de las políticas educativas de coeducación de la UNESCO en } \\
\text { países como Kenia e India (Lomba, 2015) } \\
\text { PISA como instrumento de legitimación de la reforma de la LOMCE } \\
\text { (Fernández-González, 2015) }\end{array}$ \\
\hline
\end{tabular}

Fuente: Elaboración propia

Vemos en la tabla 1, publicaciones e investigaciones actuales cuyo objeto de estudio es la Política Educativa Supranacional y que muestran la aplicación real de las diferentes líneas de estudio que podemos trazar en esta disciplina.

El origen de la política educativa supranacional lo encontramos en tres factores determinantes:

(1) los efectos de la globalización, entre los que podemos destacar el desarrollo de las TIC's, la aparición de internet o la evolución de los medios de transporte, factores que han hecho del planeta una «Aldea Global», como ha sido definido desde el último tercio del siglo XX, día de hoy, ningún sistema educativo puede ser interpretado ni entendido sin tener en cuenta esa mundialización planetaria de la información y de la comunicación;

(2) el crecimiento de la movilidad y flujos de personas que se mueven de unos sistemas nacionales a otros, bien por desarrollarse a nivel profesional, bien para obtener mejoras formativas, bien para conocer otras culturas y costumbres. Así bien en el área educativa resulta significativo el constante crecimiento de la movilidad de estudiantes, profesores, investigadores y profesionales; 
(3) el nacimiento y crecimiento exponencial de organismos internacionales que surgen a partir de la Segunda Guerra Mundial. La mayor catástrofe humana y económica de nuestra historia como especie, llevó a pensar en la necesidad de buscar nuevas formas de relacionarse entre las naciones y aparecieron nuevos marcos, supranacionales, para arbitrar el nuevo orden internacional. Si bien en el origen de estas organizaciones internacionales -a excepción de la Organización de Estados Iberoamericanos (OEI) - no figura explícitamente la educación como uno de los ámbitos de actuación (se centran en la paz, la democracia, el desarrollo y la cooperación económica), pronto entrará en su agenda política convencidos que la actuación en educación ayudaría al logro de sus objetivos.

A estos tres factores ya descritos y propuestos por Valle (2012), podríamos añadirle un cuarto factor determinante que puede explicar el impulso que ha tomado la política educativa supranacional más allá de la política educativa, como concepto tradicional, es el denominado poder blando o soft power y su posible impacto en la configuración de políticas internacionales y supranacionales (Trunkos, 2013; Matarranz y Pérez, 2016).

Este término poder blando o soft power Nye lo define como "la habilidad de obtener lo que quieres a través de la atracción antes que a través de la coerción o de las recompensas" (2004, p. 128). El poder blando configura e impone progresiva y sutilmente una realidad de actos y voluntades intangibles, que circulan, en nuestro caso transnacionalmente, y se interiorizan en el individuo y en la sociedad (Garibay, 2005). También es clarificadora la definición dada por Leylavergne y Parra (2009) quienes indican que "poder blando designa la capacidad para un actor "A" de influir en un actor "B" para que éste adopte el punto de vista del actor " $\mathrm{A}$ " por la vía de medios culturales y/o ideológicos” (p. 186).

De la mano del término poder blando, podemos destacar dos conceptos muy próximos, ley dura o hard law y ley blanda o soft law; entendemos por ley dura o hard law aquella normativa vinculante que los Estados miembros deben acatar y, por su parte, la ley blanda o soft law es la normativa no vinculante, de forma que su aplicación queda sometida a la voluntad de los gobiernos nacionales.

Podemos considerar entonces que las declaraciones, informes o recomendaciones de los organismos internacionales, son ejemplo de ley blanda, dado que, por su carácter no vinculante, no obligan a su cumplimiento a ningún país. Así mismo, cabe resaltar que, a pesar de no depender de la autoridad de un Estado, estas leyes blandas pasan, por lo general, un proceso de participación, consenso y toma de decisiones, como resultado de un diálogo entre diferentes agentes, lo que le otorga una cierta fuente de legitimidad (Padilla, 2014). En contraposición al poder blando o soft power en cuyo caso no existen procesos explícitos consensuados de construcción y ejecución de políticas.

Podríamos, en consecuencia, decir que la influencia del poder blando sería (entre otras) una de las razones instigadoras del origen de la política educativa supranacional, ya que, inmersos en una realidad cada vez más globalizada y compartida, los Estados tienden a seguir e interiorizar en su cultura las recomendaciones de organismos supranacionales (Matarranz y Pérez, 2016). Cuando estas políticas supranacionales son vistas como legítimas a ojos de los demás Estados, el poder blando se realza, así como su impacto en las políticas nacionales (Nye, 2004; Trunkos, 2013). Por tanto, este poder blando, nos muestra una "segunda cara del poder" (Nye, 1990), que de nuevo pone en entredicho las limitaciones del propio término de política en la realidad educativa actual, ya que no se realiza de forma consensuada y el ciudadano no ejerce su derecho de participación en las decisiones políticas forma activa. 
Vemos la creación de nuevos mecanismos de gobernación adaptados a este mundo globalizado y desde la perspectiva neoliberal actual (Rose, 1996). Buen ejemplo de ello son las evaluaciones internacionales (en términos anglosajones accountability) como uno de estos nuevos instrumentos de poder (Lundgreen, 2013). Algunos autores, respecto a esta corriente de evaluaciones educativas, llegan incluso a afirmar que los sistemas de evaluación educativa internacionales son en realidad productores de esta cultura global, y no consecuencia de ella (Sobe, 2015).

Estas cuestiones que, como vemos, van más allá de las formas tradicionales de política y poder, son ya realidades que forman parte de nuestras sociedades actuales y de sus formas de organización y puesta en marcha de acciones. La esfera educativa, no queda al margen de estas cuestiones, es de todos conocido que en las últimas décadas numerosos organismos internacionales han entrado en el terreno educativo (Ramírez y Matarranz, 2015), algunos ejemplos de ello los encontramos en la Organización de Estados Iberoamericanos (OEI), el Banco Mundial, la Unión Europea o la Organización de las Naciones Unidas para la Educación, la Ciencia y la Cultura (UNESCO), y los distintos programas, informes, propuestas y acciones (...) que en materia educativa se han realizado desde ellos. 


\section{BIBLIOGRAFÍA}

Aguila, R. (2008). Manual de Ciencia Política. Madrid: Ed. Trotta.

Arendt, H. (1997). ¿Qué es la política? Pensamiento contemporáneo. Barcelona: Paidós.

Colucci-Gray, L., \& Gray, D. (2014). One planet residency: Perspectives on globalisation and education. Sisyphus-Journal of Education, 2(3), 7-12.

Delors, J. (1996). La educación encierra un tesoro. Madrid: Ediciones UNESCO Santillana

Estévez, J. M. (2010). Educar: un compromiso con la memoria. Barcelona: Octaedro.

Fernández-González, N. (2015). PISA como instrumento de legitimación de la reforma de la LOMCE. Bordón Revista de Pedagogía, vol. 67 (1), pp. 165-178

Fernández-Represas, N. (2015). Política educativa de la UNESCO: Reflexiones desde un modelo de análisis supranacional. Bordón Revista de Pedagogía, vol. 67 (2), pp. 101-115

García Hoz, V. (1992). Sobre el concepto de educación personalizada y algunas derivaciones. Anales de la Real Academia de Ciencias Morales y Políticas, 69, 191-206.

Garibay, H. C. (2005). Foucaulty el poder. México: Ediciones Coyoacán.

Ibáñez Martín, J. A. (2010). ¿Llenar el vaso o encender el fuego? Viejos y nuevos riesgos en la acción educativa. Lección Inaugural del curso académico 2010-2011. Madrid: UCM.

Kumar, I. A., \& Parveen, S. (2013). Teacher Education in the Age of Globalization, Research Journal of Educational Sciences, 1(1), 8-12.

Lesourne, J. (1993). Educación y sociedad. Los desafíos del año 2000. Barcelona: Gedisa.

Leykavergne, J., \& Parra, A. (2009). La cooperación: ¿un instrumento de refuerzo de Soft Power?. El AGORA USB, 9(1), 183-209.

Lomba, L. (2015). Impacto de las políticas educativas de coeducación de la UNESCO en países como Kenia e India. Journal of Supranational Policies of Education, 3, pp. 184-201.

López, A. (2008). Retos metodológicos de la educación comparada en la sociedad global. Revista Universidad y Sociedad del Conocimiento, 5, 1-9.

Lundgreen, U. P. (2013). Pisa como instrumento político: la historia detrás de la creación del programa Pisa. Revista de curriculo y formación del profesorado, 17(2), 15-29.

Matarranz, M. (2017). Análisis supranacional de la política educativa de la unión europea 20002015. Hacia un espacio europeo de educación (tesis doctoral). Madrid: Universidad Autónoma de Madrid. 
Matarranz, M., \& Pérez, T. (2016). ¿Política Educativa Supranacional o Educación Supranacional? El debate sobre el objeto de estudio de un área emergente de conocimiento. Revista Española de Educación Comparada, 28, 91-107.

Mialaret, G. (1977). Ciencias de la educación. Barcelona: Oikos-Tau.

Miller, D. (Dir.) (1989). Enciclopedia del pensamiento politico. Madrid: Alianza Editorial.

Monarca, H. \& Mans, J. (2015). Desarrollo Profesional Docente en el Discurso de los Organismos Internacionales. Revista Española de Educación Comparada, 26, 171-189.

Morin, E. (2005). Los siete saberes necesarios para la educación del futuro. Madrid: Paidós.

Nye, J. S. (2004). Soft power: The means to success in world politics. New Hampshire: Public Affairs.

Núñez, L., \& Romero, C. (2003). Pensar la educación. Conceptos y opciones fundamentales. Madrid: Ediciones Pirámide.

Padilla, A. (2014): Principios de responsabilidad social empresarial en el ordenamiento jurídico colombiano. Revista de Derecho, 1, 51-82.

Pérez Juste, R. (2002). La evaluación de programas en el marco de la educación de calidad. XXI Revista de Educación, 4, 43-76.

Peters, R. S. (1969). El concepto de educación. Buenos Aires: Paidós.

Puelles, M. (2004). Elementos de Politica de la Educación. Madrid: Ed. UNED.

Rose, N. (2006). Governing "advanced" liberal democracies. En A. Sharma \& A. Gupta (Eds.), The anthropology of the state: A reader (pp. 144-162). Cornwall: Blackwell

Salabarría Roig, M. (2006). Los valores en la cultura política. III Conferencia Internacional La obra de Carlos Marx y los desafíos del Siglo XXI.

Sartori, G. (1993). ¿Qué es la democracia?. México: Editorial Patria.

Savater, F. (1997). El valor de educar. Madrid: Ariel.

Sobe, N. W. (2015). All that is global is not world culture: Accountability systems and educational apparatuses. Globalisation, Societies and Education, 13(1), 135-148.

Sodaro, M. J. (2006). Política y Ciencia Política. Una introducción. Madrid: Mc Graw-Hill.

Tiana, A. (2009). Por qué hicimos la Ley Orgánica de Educación. Madrid: Wolters Kluwer.

Trunkos, J. (2013). What is Soft Power Capability and How Does It Impact Foreign Policy? (PhD Student-prospectus proposal, University of South Carolina). Recuperada de: http://www.culturaldiplomacy.org/academy/content/pdf/participantpapers/2013acdusa/What-Is-Soft-Power-Capability-And-How-Does-It-Impact-Foreign-Policy--JuditTrunkos.pdf. 
Usarralde, M.J, (2015). Equidad de género en las agencias supranacionales. Evidencias educativas desde una lectura comparada. Bordón Revista de Pedagogía, vol. 67 (1), pp. 57-70.

Valle, J. M. (2006). La Unión Europea y su politica educativa. Madrid: Ministerio de Educación y Ciencia.

Valle, J. M. (2012). Supranational education: A new field of knowledge to address educational policies in a global world. Journal of Supranational Policies of Education, 1, 7-30.

Valle, J. M. (2012). La Política Educativa Supranacional: un nuevo campo de conocimiento para abordar las políticas educativas en un mundo globalizado. Revista Española de Educación Comparada, 20, 109-144. 


\section{SOBRE LOS AUTORES}

\section{María Matarranz}

Doctora Cum Laude en Educación y Licenciada en Pedagogía. Profesora del Departamento de Didáctica y Teoría de la Educación de la Universidad Autónoma de Madrid (UAM) y Profesora en la Facultad de Educación de la Universidad a Distancia de Madrid (UDIMA).

Es miembro del Grupo de Investigación sobre Políticas Educativas Supranacionales (GIPES) ${ }^{1}$

Contact information: matarranzm@gmail.com

\section{Javier M. Valle}

Doctor en Ciencias de la Educación. Premio Extraordinario de Doctorado. I Premio Nacional de Tesis Doctorales en Educación Comparada "Pedro Rosello".

Profesor Titular de la UAM, especialista en Educación Supranacional y, más concretamente, en la política educativa de la Unión Europea.

Director del Grupo de Investigación Reconocido de la UAM sobre "Políticas Educativas Supranacionales" (GIPES) en cuyo marco coordina diversos proyectos de investigación competitivos.

Publicaciones más destacadas: La Unión Europea y su política Educativa (Madrid, MEC, 2006) y "Supranational Education" (Journal of Supranational Policies of Education, no 1).

Asesor externo de EURYDICE. Miembro de TEAM-EUROPE, equipo de conferenciantes expertos en Unión Europea de la Comisión y el Parlamento Europeos. Secretario Académico de la Junta Directiva de la Sociedad Española de Educación Comparada. Miembro del Colegio Oficial de Doctores y Licenciados en Filosofía y Letras y en Ciencias de Madrid, de la Sociedad Española de Pedagogía y de la Comparative Education Society in Europe. Director de la Journal of Supranational Policies of Education, y Co-Director de la Revista Española de Educación Comparada.

Miembro del Consejo Escolar de la Comunidad de Madrid

Contact information: im.valle@,uam.es

Universidad Autónoma de Madrid

\footnotetext{
1 http://www.gipes-uam.com
} 